\title{
Delivery of Health Coaching by Medical Assistants in Primary Care
}

\author{
Zora Djuric, PhD, Michelle Segar, PhD, Carissa Orizondo, MD, Jeffrey Mann, \\ Maya Faison, BA, Nithin Peddireddy, BS, Matthew Paletta, MD, and Amy Locke, MD
}

Background: Health coaching is potentially a practical method to assist patients in achieving and maintaining healthy lifestyles. In health coaching, the coach partners with the patient, helping patients discover their own strengths, challenges, and solutions.

Methods: Two medical assistants were provided with brief training. The 12-week program consisted of telephone coaching with in-person visits at the beginning and end of the program. Coaching targeted improvements in diet, physical activity, and/or sleep habits using a self-care planning form.

Results: A total of 82 subjects enrolled in the program, $72 \%$ completed 8 weeks and $49 \%$ completed 12 weeks. Subjects who completed assessments at 12 weeks had significant weight loss despite the fact that weight loss was not a study goal. There also were improvements in diet and physical activity. Subject who completed the study were highly satisfied with the program and felt that health coaching should be available in all family medicine clinics. The main barrier providers voiced was remembering to refer patients. The medical providers indicated high satisfaction with the study and valued having coaching available for their patients.

Conclusions: Medical assistants can be trained to assist patients with lifestyle changes that are associated with improved health and weight control. (J Am Board Fam Med 2017;30:362-370.)

Keywords: Diet, Exercise, Goals, Habits, Healthy Lifestyle, Mentoring, Primary Health Care, Self Care, Telephone, Weight Loss

It has been estimated that a major portion of all chronic diseases could be prevented by diet, physical activity, and weight control. ${ }^{1}$ The Diabetes Prevention Program and Outcome Study is a hallmark example of the effectiveness of lifestyle change for prevention. The weight loss program was delivered by lifestyle coaches who were mainly

This article was externally peer reviewed.

Submitted 7 October 2016; revised 23 January 2017; accepted 6 February 2017.

From the Department of Family Medicine, University of Michigan, Ann Arbor (ZD, CO, JM, MF, NP, MP); Sport, Health, and Activity Research and Policy Center, University of Michigan, Ann Arbor (MS); and the Department of Family and Preventive Medicine, University of Utah, Salt Lake City (AL).

Funding: This study was supported by the patient-centered medical home initiative in the Department of Family Medicine, the Summer Biomedical Research Program, and the Undergraduate Research Opportunities Program at the University of Michigan.

Conflict of interest: none declared.

Corresponding author: Zora Djuric, PhD, Department of Family Medicine, University of Michigan, 1400 East Medical Center Drive, Cancer Center 4306, Ann Arbor, MI 48118-5936 (E-mail: zoralong@umich.edu). dietitians, and new cases of diabetes were reduced by $58 \%$ among high-risk patients over 3 years. ${ }^{2,3}$ Lifestyle counseling also improves cholesterol levels, blood pressure, and body weight in persons at risk for cardiovascular diseases. ${ }^{4}$ The US Preventive Services Task Force identified lifestyle counseling as a grade B recommendation for all obese individuals. ${ }^{5}$

Despite recommendations, effecting changes in lifestyle in a clinical setting with minimal resources is challenging. Encouraging healthy lifestyle changes takes on increasing importance as primary care moves toward a sharper focus on population health and disease prevention. Health coaching holds promise for use in primary care, empowering patients to discover their own path to behavior change by providing education, support, and a sense of self-efficacy rather than specific advice. ${ }^{6}$ Health coaching has led to positive patient outcomes in several studies, including weight loss, diabetes control, decreased blood pressure, and improved health behavior. ${ }^{7-12}$ Health coach- 
ing has the potential to decrease the amount of time patients spend with a physician, decrease physician follow-up, and increase satisfaction among both patients and providers as a result of the delivery of more personalized care. As an example, one study reported increased patient trust in their physician when health coaching was provided. $^{13}$

Health coaching differs from counseling in several ways. Instead of providing education and advice in a proscriptive manner, health coaching focuses on internal motivation and encouraging goal setting that is defined by the individual. The premise of this study was that information is readily available and community resources are in place to support healthy lifestyle strategies. The coach was simply the catalyst to elicit goal setting and to formulate a plan for implementation of steps to reach goals. ${ }^{14,15}$

This health coaching program targeted nutrition, physical activity, and sleep. Appropriate sleep patterns are increasingly recognized to play a role in chronic diseases and obesity. ${ }^{16}$ This health coaching was specifically designed to avoid a focus on weight loss because of the persistent problem of weight regain following loss. ${ }^{17}$ Beneficial behavior changes also may not result in immediate weight loss, which could be discouraging. Thus, we chose to focus on behaviors that underlie health. In this way, a change in the behavior, no matter how small, is celebrated and experienced as a success, rather than the weight loss that may eventually follow if the behavior is sustained.

Physicians could be trained to serve as health coaches; however, studies have shown that primary care physicians have inadequate time during visits to sufficiently address prevention and management of chronic illness. ${ }^{18,19}$ Physicians also tend to be proscriptive when providing advice. A number of other medical professionals are available to fill this role. We used medical assistants (MAs). MAs are present in virtually every practice and are already involved in providing much of the patient follow-up care in the clinic.

Few studies have used MAs for health coaching. In the case of diabetes care, which addresses prescribed self-care goals, evidence exists of improvement in self-care using health coaching with a MA. ${ }^{20}$ Among people with uncontrolled diabetes, hypertension, or hyperlipidemia, in-clinic health coaching by MAs over one year improved biomarkers of health risks. ${ }^{9}$ We explored the feasibility of training MAs to address health coaching for improved nutrition, physical activity, and sleep among the general clinic population.

\section{Methods \\ Study Subjects}

The study was approved by the University of Michigan Internal Review Board (HUM00087322) and registered at ClinicalTrials.gov (identifier NCT02201069). Eligible patients were aged $\geq 21$ years, had access to a telephone, and had a referral for health coaching (sleep, diet, or physical activity). Patients who were pregnant or trying to become pregnant were excluded.

\section{Recruitment}

Recruitment occurred from September 3, 2014, through April 15, 2016, at a large, academic practice with 21 providers; each morning and each afternoon clinic are staffed with 8 providers. Support staff (as full-time equivalents) included 5 nurses and 19 MAs. Patients who could benefit from health coaching for improvement in sleep habits, diet, or physical activity were identified by clinical staff. Patients who saw the study flyer in the clinic could self-refer. Patients were contacted by the health coach in the clinic after their health care appointment or by phone to receive more information about the study. Interested and eligible patients provided written, informed consent to participate.

\section{Health Coaching}

The Patient-Centered Medical Homes Initiative paid for 2 days/week of MA effort needed for conducting this research, study, and our institution required a bachelor's degree for the role of health educator. Therefore, both MAs had a bachelor's degree from a community college, making them better qualified than most MAs, who have only 180 hours of classroom and clinical training. The first MA left the study after a year because of maternity leave, and the second MA transitioned into the study with initial overlap in conducting the coaching. Both MAs were trained by taking the commercial Wellcoaches ${ }^{\mathrm{TM}}$ training program that focuses on motivational interviewing. The MAs also were provided with 1 hour of training by a motivational psychologist on methods to foster autonomous goal 
Figure 1. Self-care weekly planning worksheet developed for use in health coaching. This form was used by patients to formulate their own plans for better diet, physical activity, and/or sleep.

\section{Self-Care Planning and Evaluation Tool}

1. PLANNING: Using the chart, write down your specific action and "if-then" plans for the upcoming week. (Don't fill out the last two columns when planning - these are for later, when you are evaluating your plan at the end of each day.)

2. EVALUATION: Fill out the last two columns to evaluate your plans. Include what you might do differently to negotiate your self-care plan to fit within your daily life.

\begin{tabular}{|l|l|l|l|l|l|}
\hline \multicolumn{1}{|c|}{ Day } & $\begin{array}{c}\text { My action } \\
\text { plan: }\end{array}$ & $\begin{array}{c}\text { What are likely } \\
\text { challenges to my } \\
\text { action plan? }\end{array}$ & $\begin{array}{c}\text { What “if-then" } \\
\text { plan can I use to } \\
\text { negotiate these } \\
\text { challenges? }\end{array}$ & $\begin{array}{c}\text { Did my } \\
\text { plan work? }\end{array}$ & $\begin{array}{c}\text { What would I do } \\
\text { differently if I } \\
\text { could redo the } \\
\text { same day? }\end{array}$ \\
\hline Monday & & & & & \\
\hline Tuesday & & & & & \\
\hline Wednesday & & & & & \\
\hline Thursday & & & & & \\
\hline Friday & & & & & \\
\hline Saturday & & & & & \\
\hline Sunday & & & & & \\
\hline
\end{tabular}

setting and create implementation intentions, emphasizing the value of sustainable behavior change. ${ }^{21}$ Coaches were provided with a resource manual containing summaries of and web links to accepted diet, physical activity, and sleep recommendations from the US Department of Agriculture and the National Institutes of Health.

Patients self-selected target behaviors for health coaching: sleep, diet, and/or physical activity. Coaches focused on eliciting behavior change goals from subjects rather than on providing advice. Contact appointments were designed to be weekly for 4 weeks and biweekly for the subsequent 8 weeks, but subjects could request more frequent contact.

At the baseline session, the coaches asked clients to identify how they could benefit from prioritizing their own self-care among other life demands and to identify the immediate benefits of engaging in self-care behaviors such as physical activity (eg, increased energy). ${ }^{22}$ A planning and evaluation tool was developed to help patients learn how to navigate and overcome challenges to their desired selfcare behavior (Figure 1). This form was provided to each subject and reviewed during the coaching contacts.

\section{Assessments}

All anthropometric measurements were taken by a MA. Blood pressure was measured manually. Weight was measured using a digital scale. Height was measured with a wall-mounted stadiometer. Waist circumference was measured over the belly button with a tape measure.

The study questionnaire included diet questions from the Behavioral Risk Factor Surveillance System Questionnaire. ${ }^{23}$ Participants were asked about intakes of juice, fruit, and vegetables in half-cup serving sizes and about beverages in 12-oz serving sizes. We measured physical activity using a previously validated, modified version of the Godin Leisure Time Questionnaire to assess minutes of each type of physical activity. ${ }^{24,25}$

The fatigue scale (8-item Neuor-QOL Item Bank 1.0 Fatigue Short Form) was from the $\mathrm{Pa}$ tient-Reported Outcomes Measurement Information System Health Organization. ${ }^{26}$ Sleep quality used 5 items from the Patient-Reported Outcomes 
Measurement Information System Sleep Disturbance Item Bank version 1.0 ("I was alert when I woke up," "I had to force myself to get up in the morning," "I had trouble stopping my thoughts at bedtime," "I was sleepy during the daytime," and "I had trouble falling asleep at bedtime"), and 1 additional item ("I wake up in the middle of the night and have trouble falling back asleep") that is commonly used to assess sleep. This resulted in 6 items total scored on a scale of 1 to 5 . Depression was screened using the 4-item Patient Health Questionnaire, ${ }^{27}$ and stress was assessed using the 10-item Perceived Stress Scale developed by Cohen et al. ${ }^{28}$

Self-confidence for carrying out desired health behaviors was assessed using 2 items that were answered on a 5 -point scale, from strongly disagree to strongly agree. The behaviors assessed were (1) physical activity ("I can be physically active on a regular basis," "I can deal with everyday challenges that might get in the way of my physical activity plans"); (2) diet ("I can eat fruit and/or vegetables at every meal," "I can avoid foods like sweets, pop, fries, and chips"); and (3) sleep ("I can get the sleep that I need to feel good," "I can go to bed at a time that allows me to sleep enough").

Brief qualitative questionnaires were devised to assess the views of the patients, MA coaches, physicians, and support staff in order to evaluate the program. These questionnaires included questions that were answered on a 5-point scale. In addition, open-ended questions were asked in order to capture additional comments.

\section{Statistical Analyses}

All data were analyzed using SPSS software version 22 (IBM, Chicago, IL). Differences in the characteristics of subjects who did or did not complete the study were analyzed using the 2-sample $t$ test for continuous variables and the Pearson $\chi^{2}$ test for categorical variables. For changes over the 12 weeks of the study, the paired $t$ test was used. $P$ values $<.05$ were considered statistically significant.

\section{Results}

\section{Enrollment and Retention}

A total of 82 subjects enrolled in the study (Table 1). Retention over 8 weeks was $72 \%$, and retention for 12 weeks of coaching was $49 \%$. Most of the
Table 1. Accrual, Retention, and Number of Coaching Contacts in the My Health Coach Study*

\begin{tabular}{lr}
\hline Study Data & No. \\
\hline Referred patients & 167 \\
Subjects enrolled & 82 \\
Coaching goals selected & \\
$\quad$ Physical activity only & 9 \\
Diet only & 12 \\
Physical activity and diet & 61 \\
Sleep, physical activity, and/or diet ${ }^{\dagger}$ & 24 \\
Subjects who completed 8 weeks & 59 \\
Subjects who completed 12 weeks & 40 \\
Attempted calls & 719 \\
Completed calls & 500 \\
Contacts in person & \\
\hline
\end{tabular}

*Study enrollment occurred September 3, 2014, through April 15, 2016, in a large, multiprovider family medicine practice.

${ }^{\dagger}$ Sleep alone was not selected by any study participant.

†Study contacts were mainly by telephone appointment, but if a subject was in the office while in the study, the coaching contact was completed in person.

coaching contacts were by phone, but some were completed in person if the subject was returning to the office for medical care. The number of contacts per subject among those who completed 12 weeks of coaching was an average of 7.8 contacts, which was close to the planned 8 contacts.

Of the 82 subjects enrolled, 2 subjects did not complete any of the baseline questionnaires. For this reason, the baseline data presented are based on 80 subjects for all variables, with the exception of sex and race, which were collected for all 82 subjects for institutional review board reporting purposes. Most of the subjects were middle-aged women, well educated, white, and obese (Table 2).

During the 12-week study, 41 participants withdrew. When comparing participants who withdrew from the study with those who completed the study, participants who completed the study were significantly more likely to be male $(P=.027)$ and married or in a committed relationship $(P=.003)$ (Table 2). Differences in confidence to carry out the targeted behaviors (physical activity, diet, or sleep), stress, fatigue, and depression were not significantly different by study completion status (data not shown).

\section{Coaching Implementation}

The initial coaching session typically lasted 1 hour (mean, 54 minutes; standard deviation, 17 minutes). 
Table 2. Characteristics of Subjects Who Did or Did Not Complete 12 Weeks of Health Coaching

\begin{tabular}{|c|c|c|c|}
\hline Baseline Characteristics & $\begin{array}{l}\text { Subjects Who Completed } \\
\text { the Study }(\mathrm{n}=39)\end{array}$ & $\begin{array}{l}\text { Subjects Who Withdrew } \\
\qquad(\mathrm{n}=41)\end{array}$ & $P$ Value* \\
\hline Age, years & $53(11)$ & $51(10)$ & .484 \\
\hline Female sex ${ }^{\dagger}$ & 30 & 39 & .027 \\
\hline Body mass index $\left(\mathrm{kg} / \mathrm{m}^{2}\right)$ & $34.5(7.0)$ & $35.1(7.6)$ & .705 \\
\hline Caucasian race $^{\dagger}$ & 28 & 27 & .091 \\
\hline $\begin{array}{l}\text { Married/in a committed } \\
\text { relationship }\end{array}$ & 33 & 22 & .003 \\
\hline College graduate & 32 & 33 & .543 \\
\hline Physical activity $(\mathrm{min} / \mathrm{wk})^{\ddagger}$ & $324(291)$ & $303(388)$ & .787 \\
\hline $\begin{array}{l}\text { Moderate or strenuous physical } \\
\text { activity }(\mathrm{min} / \mathrm{wk})^{\ddagger}\end{array}$ & $107(123)$ & $158(345)$ & .391 \\
\hline $\begin{array}{l}\text { Fruit, vegetable, and bean } \\
\text { intake (servings/day) }\end{array}$ & $4.7(4.0)$ & $3.7(2.4)$ & .129 \\
\hline $\begin{array}{l}\text { Pop and sugary beverage intake } \\
\text { (servings/day) }\end{array}$ & $0.30(0.48)$ & $0.39(1.00)$ & .568 \\
\hline Sleep score ${ }^{\|}$ & $16.8(3.6)$ & $16.9(4.2)$ & .902 \\
\hline
\end{tabular}

Data shown are mean (standard deviation) or number of subjects.

*Two-sample $t$ tests were used to compare the characteristics of subjects who did or did not complete the study. The Pearson $\chi^{2}$ test was used to calculate the exact 2 -sided p-value for categorical variables.

${ }^{\dagger}$ Two subjects- one who completed the study and one who did not- did not fill out an Health Status Questionnaire (HSQ) at baseline, and demographic data are not available for these individuals, except for sex and race, which were collected outside of questionnaires, as required for institutional review board reporting. For sex and race, the data shown are therefore for 40 subjects who completed the study and 42 subjects who withdrew. Only 4 smokers were in the study, and none of them completed it.

${ }^{\ddagger}$ Physical activity was from the previously validated, modified version of the Godin Leisure Time Questionnaire, which was used to assess minutes of each type of physical activity. ${ }^{24,25}$

${ }^{\S}$ Diet was assessed using questions from the 2013 Behavioral Risk Factor Surveillance System Questionnaire. ${ }^{23}$ Intakes of juice, fruit, beans, dark green vegetables, orange vegetables, and other vegetables $\left(1 / 2^{-}\right.$cup serving sizes) were asked about. Regular and diet soda, and sugar-sweetened beverages (12-oz serving sizes) were asked about.

"Sleep was assessed using 5 items from the PROMIS Sleep Disturbance Item Bank version 1.0, and 1 additional item as described in the Methods. This resulted in 6 items total scored on a scale of 1 to $5^{26}$.

Follow-up coaching sessions averaged 14 minutes each (standard deviation, 6 minutes). Compliance with the telephone coaching appointments was reasonably good, and $70 \%$ of attempted calls were completed with study subjects. The MA health coaches had set aside time for these coaching calls.

As the study progressed, the clinic physicians indicated that they wanted more information regarding health coaching of their patients so that they could follow up appropriately. This was resolved by using the medical record to notify physicians when their patients were enrolled in the study. In addition, the health coaching notes were incorporated into the electronic medical record.

\section{Coaching Goals}

Study subjects were asked to select $\geq 1$ coaching goal at study enrollment: improving diet, improving physical activity, or improving sleep. Most subjects ( 65 of 82 ) selected coaching for $\geq 2$ goals, and none chose to focus on sleep alone (Table 1).
Coaching for improving both diet and physical activity was the most popular choice (61 of 82 subjects; 74\%). Subjects had the option of changing their coaching goals while in the study, but this had little effect on the nature of the goals selected. Of the 80 subjects with at least one coaching call, 65 of $80(81 \%)$ selected coaching for both diet and physical activity.

The baseline questionnaire asked about motivation to join the study. Weight loss was not the stated focus of the coaching program, but $45 \%$ of participants cited weight loss as a reason for enrolling in health coaching. Other reasons included wanting to work on sleep (11\%), exercise (31\%), diet quality (38\%), increasing motivation for behavior change $(15 \%)$, and general health $(21 \%)$.

\section{Subject Outcomes}

Of the 40 subjects who completed 12 weeks of coaching, 33 completed a clinic visit at that time for 
Table 3. Study Measures for Subjects Who Completed 12 Weeks of Health Coaching

\begin{tabular}{|c|c|c|c|}
\hline Assessment & Baseline & 12 Weeks & $P$ Value $^{*}$ \\
\hline Body mass index $\left(\mathrm{kg} / \mathrm{m}^{2}\right)$ & $34.1(7.0)$ & $33.4(7.0)$ & .014 \\
\hline Waist circumference $(\mathrm{cm})$ & $104(16)$ & $100(16)$ & $<.001$ \\
\hline Systolic blood pressure (mm) & $116(10)$ & $115(9)$ & .385 \\
\hline Diastolic blood pressure (mm) & $70(8)$ & $66(8)$ & .031 \\
\hline Fruits, vegetables, and beans ( $1 / 2-$ cup servings/day) & $5.1(3.8)$ & $5.8(3.9)$ & .291 \\
\hline Sugary beverages (12-oz servings/day) & $0.35(0.51)$ & $0.17(0.31)$ & .039 \\
\hline Total physical activity (min/week) & $340(292)$ & $476(388)$ & .007 \\
\hline Moderate or strenuous physical activity (min/week) & $123(124)$ & $207(263)$ & .061 \\
\hline Sleep score & $17.2(3.5)$ & $15.9(3.9)$ & .016 \\
\hline Stress score ${ }^{\dagger}$ & $18.3(7.6)$ & $16.8(8.3)$ & .229 \\
\hline Fatigue score ${ }^{\ddagger}$ & $22.7(7.8)$ & $20.9(7.8)$ & .096 \\
\hline Confidence to carry out physical activity ${ }^{\S}$ & $6.8(1.6)$ & $7.7(1.7)$ & .002 \\
\hline Confidence for improving $\operatorname{diet}^{\S}$ & $7.3(1.4)$ & $7.2(2.0)$ & .756 \\
\hline
\end{tabular}

Data are mean (standard deviation) for 33 subjects who completed measures at both baseline and 12 weeks. The data include all subjects, regardless of coaching goal. Of the 33 subjects with completed 12-week data, 32 subjects received coaching that included a physical activity goal, 26 subjects with a diet goal, and 7 subjects with a better sleep goal.

${ }^{*} P$ values for differences over time are from paired $t$ tests for subjects who completed 12 weeks of health coaching. A total of 33 subjects had paired anthropometric measures, and 32 subjects had paired questionnaire data. Physical activity, diet, and sleep were assessed using the methods described in Table 2 .

${ }^{\dagger}$ Stress was assessed using the 10-item Perceived Stress Scale developed by Cohen et al. ${ }^{28}$

${ }^{\ddagger}$ Fatigue was assessed using the Neuor-QOL Item Bank 1.0 Fatigue Short Form (8 items) from the Patient-Reported Outcomes Measurement Information System (PROMIS) health organization. ${ }^{26}$

${ }^{\S}$ Confidence for carrying out the indicated health behaviors was assessed using a study-specific questionnaire of 2 items that were answered on a 5 -point scale (see the Methods).

study assessments. Changes before and after coaching were evaluated using the paired $t$ test (Table 3 ). Body mass index decreased significantly $(P=.014)$, as did weight circumference $(P<.001)$, among the 33 subjects with anthropometric measures completed at both time points. No significant change occurred in systolic blood pressure, but diastolic blood pressure decreased significantly $(P=.031)$. Sleep quality score $(P=.016)$ also improved, with a trend toward decreased fatigue $(P=.096)$.

Total physical activity increased significantly by 136 minutes/week, and there was a trend toward an increase in moderate and vigorous activity to 84 minutes/week. Confidence to achieve improved physical activity, but not diet, improved significantly (Table 3). Changes in diet were small. Mean intake of sugary beverages at baseline was low, and this decreased by about half after 12 weeks. Intakes of fruits, vegetables, and beans, however, were not significantly increased for total intake (shown in Table 3), nor for individual items (data not shown). The largest increase was in the consumption of dark green vegetables, which increased from 1.05 to 1.41 servings/day $(P=.09)$. The outcomes in subgroups defined by whether diet or physical ac- tivity was a health coaching goal (data not shown) were similar to that of the total study group, likely because the majority of subjects chose to work on both diet and physical activity goals.

\section{Study Evaluations by Clinic Staff and Study Subjects}

Questionnaires were completed by 11 physicians and physician extenders (Table 4). The majority indicated that recruiting patients for the study was easy, that it did not impede patient flow, and that they liked having health coaching available. Many providers (45\%) indicated that remembering to refer to the study was difficult. Only a minority thought that health coaching should be done by staff other than MAs.

The 9 MAs who completed study evaluation questionnaires also showed an overall positive impression of having health coaching in the clinic and felt that it did not impede patient flow (Table 5). Half thought that patients received useful information from health coaching. The majority of MAs felt that other staff would be more appropriate as health coaches, and only one third of MAs indicated that they would enjoy being health a coach. 
Table 4. Study Evaluation by Health Care Providers at the Practice $(n=11)$ after the My Health Coach Study Was Completed

\begin{tabular}{lc}
\hline Question & $\begin{array}{c}\text { Providers Who Agree } \\
\text { or Mostly Agree (n)* }\end{array}$ \\
\hline $\begin{array}{l}\text { Recruiting for the study was easy. } \\
\text { The study impeded patient flow. }\end{array}$ & 9 \\
$\begin{array}{l}\text { It took too much time to explain the } \\
\text { study to patients. }\end{array}$ & 1 \\
$\begin{array}{l}\text { It was hard to remember to mention } \\
\text { the study to patients. }\end{array}$ & 5 \\
$\begin{array}{l}\text { Patients thought it was helpful to } \\
\text { have the study available. }\end{array}$ & 8 \\
$\begin{array}{l}\text { I would feel comfortable supervising } \\
\text { an MA health coach. }\end{array}$ & 7 \\
$\begin{array}{l}\text { Health coaching should be done by } \\
\text { other staff, not MAs. }\end{array}$ & 2 \\
$\begin{array}{l}\text { I liked having health coaching } \\
\text { available for our patients who } \\
\text { need it. }\end{array}$ & 10 \\
\hline
\end{tabular}

*The survey questions were answered on a 5-point Likert-type scale, with responses of do not agree, mostly disagree, neutral, mostly agree, or agree.

${ }^{\dagger}$ One provider left this item blank; the rest were either neutral $(n=4)$ or disagreed/mostly disagreed.

${ }^{\ddagger}$ One provider was neutral about this item; the rest agreed or mostly agreed.

MA, medical assistant.

Study evaluations were completed by 34 of 40 subjects who completed 12 weeks of the study. The results were overwhelmingly positive, as shown in Table 6. Subjects indicated that they liked the

Table 5. Study Evaluation by Medical Assistants Other Than Those Acting as Health Coaches $(n=9)$ after the My Health Coach Study Was Completed

\begin{tabular}{ll}
\hline Question & $\begin{array}{c}\text { MAs Who Agree or } \\
\text { Mostly Agree (n)* }\end{array}$ \\
\hline $\begin{array}{l}\text { I would enjoy being a health coach. } \\
\text { MAs should be health coaches. }\end{array}$ & 3 \\
$\begin{array}{l}\text { Recruiting for health coaching interfered } \\
\text { with patient flow in our practice. }\end{array}$ & 0 \\
$\begin{array}{l}\text { Patients thought it was helpful to have } \\
\text { health coaching. }\end{array}$ & 5 \\
$\begin{array}{l}\text { Patients gave good comments about the } \\
\text { study. }\end{array}$ & 5 \\
$\begin{array}{l}\text { Health coaching should be done by staff } \\
\text { other than MAs. }\end{array}$ & 6 \\
$\begin{array}{l}\text { It was a good thing to have health } \\
\text { coaching available. }\end{array}$ & 6 \\
\hline
\end{tabular}

*The survey questions were answered using a 5-point Likerttype scale, with responses of do not agree, mostly disagree, neutral, mostly agree, or agree. MA, medical assistant.
Table 6. Study Evaluation by 34 Subjects Who Completed 12 Weeks of Health Coaching

\begin{tabular}{|c|c|}
\hline Question & $\begin{array}{l}\text { Subjects Who Agree or } \\
\text { Mostly Agree (n)* }\end{array}$ \\
\hline $\begin{array}{l}\text { I like the changes in my life from } \\
\text { having a health coach. }\end{array}$ & 31 \\
\hline $\begin{array}{l}\text { I made more changes with the } \\
\text { health coach versus what I } \\
\text { could have done on my own. }\end{array}$ & 29 \\
\hline Health coaching was a bother. & 1 \\
\hline $\begin{array}{l}\text { Health coaching took too much } \\
\text { time. }\end{array}$ & 0 \\
\hline $\begin{array}{l}\text { I wanted more time with the } \\
\text { health coach. }\end{array}$ & 12 \\
\hline $\begin{array}{l}\text { I liked the regular contacts with } \\
\text { the health coach. }\end{array}$ & 32 \\
\hline I used self-monitoring of diet. & 27 \\
\hline $\begin{array}{l}\text { I used self-monitoring of physical } \\
\text { activity. }\end{array}$ & 29 \\
\hline $\begin{array}{l}\text { I intend to keep doing what the } \\
\text { coach helped me change. }\end{array}$ & 32 \\
\hline $\begin{array}{l}\text { I would recommend health } \\
\text { coaching to my friends and } \\
\text { family. }\end{array}$ & 31 \\
\hline $\begin{array}{l}\text { I think health coaching should be } \\
\text { part of every family medicine } \\
\text { doctor's office. }\end{array}$ & 31 \\
\hline $\begin{array}{l}\text { I intend to continue with health } \\
\text { coaching. }\end{array}$ & 21 \\
\hline
\end{tabular}

*The survey questions were answered using a 5-point Likerttype scale, with responses of do not agree, mostly disagree, neutral, mostly agree, or agree.

changes in their life, made more changes than they could have on their own, and that they intend to maintain the behaviors. Of the free-text comments, 18 subjects wanted an enhanced program with a greater frequency of contacts, more written information, and/or more guidance on goal setting. All but one of the subjects either strongly agreed or mostly agreed that health coaching should be part of every family medicine clinic.

\section{Discussion}

This pilot study evaluated whether MAs with brief formal training could conduct a health coaching program aimed at improved nutrition, physical activity, and sleep for patients in a primary care practice. The coaching method focused on eliciting goal setting and creating implementation intentions using a form developed for this study (Figure 1). In this way, subjects identified for themselves how to accomplish their own goals. Although the study was small and did not focus on weight loss, 
significant changes in body mass index and several other study measures were noted (Table 3). Significant improvements also occurred in physical activity, intake of sugary beverages, and sleep quality.

This was a pilot study, and assessments were not done before 12 weeks. In clinical practice, the duration of health coaching may be flexible, ranging from a one-time consultation to long-term followup, especially given that different patients may have different needs. This study did have better subject retention over 8 versus 12 weeks (Table 1 ), indicating that a brief coaching intervention might be more realistic within an office setting. For effecting larger lifestyle changes, more intensive programs are more effective. ${ }^{29}$ Given the limitations of what can be offered through primary care, we addressed this by providing referrals to community and medical resources, but few subjects were interested in programs that required payment.

Subjects who undertook health coaching were highly satisfied with the program (Table 6), but uptake and retention into the health coaching program from this large practice was modest (Table 1). This might have been improved if methods to refer to health coaching were streamlined and more integrated into clinic visits. Providers did indicate that remembering to refer patients was a barrier (Table 4). Despite this, most providers indicated that it was beneficial to have health coaching available.

This study was accomplished by 2 MAs with degrees from community colleges and who were provided with minimal training in health coaching. Other MAs at this practice who filled out surveys were not interested in acting as health coaches (Table 5). This could stem from a lack of a relevant educational foundation and/or a lack of interest or skills in entering a coaching relationship with patients. The MAs conducting this study both had some prior training in nutrition. Conceivably, this type of health coaching could be conducted by any other clinical staff, such as social workers or nurses, who have the interpersonal skills to work with patients one-on-one-and an interest in doing so. In addition, instead of having designated times for health coaching, better integration with clinic duties might be viewed more favorably.

\section{Conclusions}

Health coaching could prove to be a cost-effective method for improving the health of patient popu- lations, and it could reduce physician time spent counseling patients. The results indicate that both providers and patients were highly satisfied with having health coaching available in the practice. Although not all patients are interested in health coaching, for the subset of patients who are interested, this could be one method to start addressing the overall health of the practice population.

The authors thank all the individuals who volunteered for the health coaching study and all the clinic staff for facilitating the study. Heather Moore and Jessica McKenna conducted the health coaching and collected study data. Alicia Michelson created the coaching resource manual. The authors thank Mack Ruffin for helpful discussions in setting up the study, Michael Fetters for discussion of qualitative surveys, and both Jessyca Judge and Riley Engstrom for assisting with the physical activity data analysis.

To see this article online, please go to: http://jabfm.org/content/ 30/3/362.full.

\section{References}

1. Diet, nutrition and the prevention of chronic diseases. WHO technical report series 916. Report of a joint WHO/FAO expert consultation. Geneva: World Health Organization; 2003. Available from: http://apps.who.int/iris/bitstream/10665/42665/1/ WHO_TRS_916.pdf. Accessed March 27, 2017.

2. Knowler WC, Barrett-Connor E, Fowler SE, et al. Reduction in the incidence of type 2 diabetes with lifestyle intervention or metformin. N Engl J Med 2002;346:393-403.

3. Diabetes Prevention Program Research Group. The Diabetes Prevention Program (DPP): description of lifestyle intervention. Diabetes Care 2002;25:2165-71.

4. Lin JS, O'Connor E, Evans CV, Senger CA, Rowland MG, Groom HC. Behavioral counseling to promote a healthy lifestyle in persons with cardiovascular risk factors: a systematic review for the US Preventive Services Task Force [Internet]. Ann Intern Med 2014;161:568-78.

5. U.S. Preventive Services Task Force. Final recommendation statement. Obesity in adults: screening and management; 2012. Available from: https:// www.uspreventiveservicestaskforce.org/Page/Document/RecommendationStatementFinal/obesity-inadults-screening-and-management. Accessed March $27,2017$.

6. Olsen JM, Nesbitt BJ. Health coaching to improve healthy lifestyle behaviors: an integrative review. Am J Health Promot 2010;25:e1-12.

7. Leahey TM, Wing RR. A randomized controlled pilot study testing three types of health coaches for obesity treatment: professional. peer, and mentor. Obesity (Silver Spring) 2013;21:928-34. 
8. Safford MM, Andreae S, Cherrington AL, et al. Peer coaches to improve diabetes outcomes in rural Alabama: a cluster randomized trial. Ann Fam Med 2015;13(Suppl 1):S18-26.

9. Willard-Grace R, Chen EH, Hessler D, et al. Health coaching by medical assistants to improve control of diabetes. hypertension, and hyperlipidemia in lowincome patients: a randomized controlled trial. Ann Fam Med 2015;13:130-8.

10. Sharma AE, Willard-Grace R, Hessler D, Bodenheimer T, Thom DH. What happens after health coaching? Observational study 1 year following a randomized controlled trial. Ann Fam Med 2016;14:200-207.

11. Margolius D, Bodenheimer T, Bennett H, et al. Health coaching to improve hypertension treatment in a low-income, minority population. Ann Fam Med 2012;10:199-205.

12. Frates EP, Moore MA, Lopez CN, McMahon GT. Coaching for behavior change in physiatry. Am J Phys Med Rehabil 2011;90:1074-82.

13. Thom DH, Hessler D, Willard-Grace R, et al. Does health coaching change patients' trust in their primary care provider? Patient Educ Couns 2014;96: 135-8.

14. Djuric Z, Ellsworth JS, Ren J, Sen A, Ruffin MT 4th. A randomized feasibility trial of brief telephone counseling to increase fruit and vegetable intakes. Prev Med 2010;50:265-71.

15. Armitage CJ, Arden MA. A volitional help sheet to increase physical activity in people with low socioeconomic status: a randomised exploratory trial. Psychol Health 2010;25:1129-45.

16. Kohansieh M, Makaryus AN. Sleep deficiency and deprivation leading to cardiovascular disease. Int J Hypertens 2015;2015:615681.

17. Barte JC, ter Bogt NC, Bogers RP, et al. Maintenance of weight loss after lifestyle interventions for overweight and obesity, a systematic review. Obes Rev 2010;11:899-906.

18. Yarnall KS, Pollak KI, Ostbye T, Krause KM, Michener JL. Primary care: is there enough time for prevention? Am J Public Health 2003;93:635-41.

19. Ostbye T, Yarnall KS, Krause KM, Pollak KI, Gradison M, Michener JL. Is there time for man- agement of patients with chronic diseases in primary care? Ann Fam Med 2005;3:209-14.

20. Ruggiero L, Riley BB, Hernandez R, et al. Medical assistant coaching to support diabetes self-care among low-income racial/ethnic minority populations: randomized controlled trial. West J Nurs Res 2014;36:1052-73.

21. Segar ML. No sweat: how the simple science of motivation can bring you a lifetime of fitness. New York: Amacon; 2015.

22. Segar ML, Guerin E, Phillips E, Fortier M. From a vital sign to vitality: selling exercise so patients want to buy it. Curr Sports Med Rep 2016;15:276-81.

23. Centers for Disease Control and Prevention (CDC). Behavioral Risk Factor Surveillance System Survey Questionnaire. Atlanta, Georgia: U.S. Department of Health and Human Services, Centers for Disease Control and Prevention, 2013. Available from https://www.cdc.gov/brfss/questionnaires/index.htm

24. Godin G, Shephard RJ. Godin Leisure-Time Exercise questionnaire. Med Sci Sports Exerc 1997; 29(June Suppl): S36-8.

25. Segar ML, Eccles JS, Richardson CR. Rebranding exercise: closing the gap between values and behavior. Int J Behav Nutr Phys Act 2011;8:94.

26. Cella D, Yount S, Rothrock N, et al. The PatientReported Outcomes Measurement Information System (PROMIS): progress of an NIH Roadmap cooperative group during its first two years. Med Care 2007;45:S3-11.

27. Kroenke K, Spitzer RL, Williams JB, Lowe B. An ultra-brief screening scale for anxiety and depression: the PHQ-4. Psychosomatics 2009;50: 613-21.

28. Cohen S, Kamarck T, Mermelstein R. A Global measure of perceived stress. J Health Soc Behav 1983;24:385-96.

29. Balk EM, Earley A, Raman G, Avendano EA, Pittas AG, Remington PL. Combined diet and physical activity promotion programs to prevent type 2 diabetes among persons at increased risk: a systematic review for the Community Preventive Services Task Force. Ann Intern Med 2015;163:437-51. 